Research Article

\title{
Selection of Unmanned Aerial Vehicles by Using Multicriteria Decision-Making for Defence
}

\author{
Mustafa Hamurcu and Tamer Eren (iD \\ Department of Industrial Engineering, Kirıkkale University, Kırıkkale, Turkey \\ Correspondence should be addressed to Tamer Eren; teren@kku.edu.tr
}

Received 18 March 2020; Revised 27 May 2020; Accepted 28 May 2020; Published 17 June 2020

Academic Editor: Ming-Sheng Liu

Copyright (C) 2020 Mustafa Hamurcu and Tamer Eren. This is an open access article distributed under the Creative Commons Attribution License, which permits unrestricted use, distribution, and reproduction in any medium, provided the original work is properly cited.

\begin{abstract}
The unmanned systems have been seeing a significant boom in the last ten years in different areas together with technological developments. One of the unmanned systems is unmanned aerial vehicles (UAVs). UAVs are used for reconnaissance and observation in the military areas and play critical role in attack and destroy missions. These vehicles have been winning more features together with developing technology in todays world. In addition, they have been varying with different features. A systematic and efficient approach for the selection of the UAV is necessary to choose a best alternative for the critical tasks under consideration. The multicriteria decision-making (MCDM) approaches that are analytic processes are well suited to deal intricacy in selection of alternative vehicles. This study also proposes an integrated methodology based on the analytic hierarch process (AHP) and technique for order preference by similarity to ideal solution (TOPSIS) to evaluate UAV alternatives for selection process. Firstly, AHP, a MCDM method, is used to determine the weights of each critical factor. Subsequently, it is utilized with the TOPSIS approach to rank the vehicle alternatives in the decision problem. Result of the study shows that UAV-1 was selected as the most suitable vehicle. In results, it is seen that the weights of the evaluation criteria found by using AHP affect the decisionmaking process. Finally, the validation and sensitivity analysis of the solution are made and discussed.
\end{abstract}

\section{Introduction}

Unmanned aerial vehicles (UAVs) are named such as remotely piloted vehicles, drones, robot planes, and pilotless aircraft, and in many ways. UAVs can fly autonomously or semiautonomously [1]. UAVs became an important element of many modern militaries and various civilian areas. Demands have been increasing for a variety of types of unmanned vehicles due to their success on battlefields. At the same time, they have capabilities such as persistent surveillance, tactical and combat reconnaissance, resilience together with its low benefit risk, and low cost. Increasing use of these vehicles is rising alongside increasing demands for battlefield intelligence, tighter defence budgets of countries, faster operation tempos, and lowered tolerance for casualties in the defence area. Besides, UAVs are also emerging as a suitable vehicle for a wide range of civil applications such as disaster monitoring and atmospheric observation [2]. As in developed countries, Turkey is also developing UAVs for defence and civilian usage.

UAVs had been mainly developed for military applications and military areas a few years ago. However, now, they have composed serious enhancements in the design and capabilities of UAVs with their varying size due to technological advancements in robotics. Today, UAVs' numerous civil applications have recently emerged due to their reliability and operation with a very good level of flight stability. UAVs have some advantages according to their alternatives, such as a helicopter. These advantages are required to reach places that are difficult to access, long periods of repetitive work, or operating in dangerous conditions, especially for extended periods of time or under stressful conditions and in risky tasks $[3,4]$. So, these advantages had ensured to use these vehicles widely. The architecture of a normal UAV consists of different five components that are the flight system, the control system, the monitoring system, the data processing system, and the landing system. 
The selection of the best UAVs with developing technology is very important in defence and affects the ability and the necessity of modern armies as well. Being able to perform reconnaissance and surveillance missions in the most effective and efficient way with well-chosen UAVs is depended on decisions of planners and managers. It is very important to create and invent them, but they are varied with developing technology day by day. Thus, a multicriteria selection process is needed for the best UAV decision with developing technology.

The main objective of this study is to propose a systematic MCDM model to help in the defence area for the selection of the most suitable UAV among a set of available alternatives. Selecting a new UAV is a strategic decision-making process that has a high complexity because of the criteria, which must be considered simultaneously. Besides, most of these criteria affect each other, are contradictory, and an increase in one of the criteria's compliance might reduce the compliance of the other. So, in order to select the best UAV among the alternatives on the market, we need to consider various evaluation criteria. The MCDM methods help to choose the best alternative by considering various criteria and by evaluating all the alternatives. The academic literature has some examples of the application of the MCDM in the defence field. Some of them are evaluating naval tactical missile systems with fuzzy AHP [5]; selection of attack helicopters by AHP [6]; evaluation of the best main battle tank with fuzzy decision theory $[7,8]$; weapon selection by using AHP and TOPSIS [9], goal programming [10]; ELECTRE (elimination and choice translating reality) [11]; evaluating the military training aircraft by using MCDM under fuzzy logic $[12,13]$; using MCDM methods for determination of the best military cargo aircraft [14]; selection of investment projects in the defence industry [15]; and military airport location selection by using the hybrid application of AHP-PROMETHEE(Preference Ranking Organisation Method for Enrichment Evaluation-) VIKOR (Serbian: Vise Kriterijumska Optimizacija I Kompromisno Resenje) methods [16]. Although UAVs play an important role in the design of an effective defence system for the military area, the academic literature about the selection of UAVs is limited. The study described in this paper has two specific objectives: (1) to introduce and describe the importance of UAV technologies and their applications; (2) to offer an analytic process that is based on AHP and TOPSIS methods for the best selection among the alternative UAVs to help decision makers in the defense area.

The remainder of this study is structured as follows: the literature review about UAVs is presented in Section 2. In Section 3, AHP and TOPSIS, multicriteria decision-making methods, are explained. The selection process by using AHP and TOPSIS is made among the various UAVs in Section 4. Conclusions are presented in Section 5.

\section{UAVs in the Literature}

Although UAVs are developed for military purposes, including reconnaissance and attack roles, they are quickly gaining popularity worldwide in various civil areas. However, now, they are used in lots of areas. UAV-based systems have many advantages according to manned air vehicles: first, the cost of use related to the low purchase, management, and operation costs. They can yield high-resolution images which are useful for traffic analysis based on video image processing. UAVs have some disadvantages such as low battery duration, battery life, limited UAV payload, vegetation, buildings, urban canyons, limited take-off mass, limited wing surface, limited wing loading, and no-fly zones which affect negatively. So, their applications for this field are limited and influenced by some factors affecting their performance, such as weather conditions should be mentioned, technical instrumental problems, and physical obstacles [17].

UAVs are widely used, especially in traffic and the construction industry. UAVs have been used for various aims such as safety/security monitoring, inspections, surveying, and aerial photography in the construction industry [18]. In traffic, there are applications such as to obtain detailed traffic information on real time [19]; to evaluate traffic flow conditions in urban areas using videos through the UAV [20]; and to estimate traffic flow parameters of a road intersection through a video image processing technique using an UAV [21]. Lee et al. mentioned about traffic and roadway incident monitoring via the UAV [22]. Khan et al. presented an extensive systematic and practical study on how to conduct an UAV-based traffic study [23]. Salvo et al. developed a new methodology to evaluate the real traffic flow conditions. In their methodology, they used the videos acquired by UAVs [20]. Barmpounakis et al. aimed to review research dedicated to using unmanned aerial systems in transportation in their study. They mentioned the advantages of the airborne video as a means for acquiring highquality naturalistic data for both practitioners and researchers in their study [24].

Besides, these UAV applications are applied in different areas such as inspection of critical linear infrastructure such as oil and gas pipelines or electrical transmission lines and inspection of wind turbine blades by UAVs with imaging. UAVs are also used in the real-estate industry on the purpose of conducting aerial surveys and mapping of planned developments or to document transactions. At the same time, UAVs are being used in decision-making in agriculture on whether crops need to be watered and where to apply the fertilizer. Also, Gül [25] mapping operations in open-pit mines are made by using the UAV Erdelj and Natalizio search review of main disaster management applications with UAV [26].

There are some papers about UAVs and their various applications in the literature. Hassanalian and Abdelkefi gave some brief information related to the civil uses of UAV/ drones and their fields of use. Also, they provided comprehensive information on the current status of the legal frames and regulations in Turkey and in the world [27]. Akgül et al. evaluated UAV and its systems. At the same time, they evaluated the usage of these vehicles for the forestry area [28]. Wu et al. discussed the development of a multiobjective mission flight planning algorithm for unmanned aerial system (UAS) operations within the National Airspace System (NAS) in their study [29]. Wu et al. presented a system for automated mission planning with a view to operate UAVs. Decision variables for their system were fuel consumption, flight time, wind and weather conditions, 
terrain elevation, airspace classification, and the flight trajectories of other aircrafts [30]. Arıca et al. presented a multicriteria path planning model for UAVs. Their model helps in the planning of optimal paths in terms of time, distance, and fuel consumption [31]. Caner demonstrated the pros and cons of UAVs compared with manned aircraft in his study. Besides, he provided information about the historical developments that have occurred and new technologies in the UAV [32].

Kirac1 and Bakır focused on the selection of the aircraft to determine the most suitable aircraft for airline companies with different flight networks and different flight destinations with the TOPSIS method [33]. Ercan and Gencer investigated the literature on "dynamic route planning" for unmanned aerial systems [34]. Lin and Hung selected military UAVs using the fuzzy weighted average algorithm. They used three main criteria in their study that are mission flexibility, operational suitability, and operational assessment [35].

Besides, some researchers, as distinct from the selection of UAVs, studied about aircraft type selection with multicriteria decision-making methods [36-38]. See et al. presented a multiattribute methodology for selecting the best aircraft among a set of alternatives. The authors used the method of hypothetical equivalents and inequivalents. They used three criteria: speed, range, and the number of passengers [39]. Yeh and Chang proposed a fuzzy multicriteria decision-making algorithm with group decisionmaking for evaluation of the performance of each aircraft. Their study that the performance of each aircraft is evaluated through fuzzy rating used three main criteria and eleven subcriteria (main criteria: technological advances, social responsibility, and economic efficiency; subcriteria: aircraft maintenance capability, pilot adaptability, aircraft reliability, maximum range, passengers' preference, the level of noise, operational productivity, airline fleet economy of scale, operating cost, purchasing price, and corporate strategy) [40]. Gomes et al. proposed a fuzzy stochastic approach for the selection of aircraft. NAIADE method (Novel Approach to Imprecise Assessment and Decision Environments) was used in their evaluation process based on three criteria (financial, logistics, and quality), further articulated to twelve subcriteria (acquisition cost, liquidity, operating costs, range, flexibility, cruising speed, replacement parts availability, landing and take-off distance, comfort, avionics, availability, and safety) [41]. Bruno et al. proposed a model aircraft evaluation in their study. The model proposed includes four main criteria (economic performance, technical performance, aircraft interior quality, and environmental impact) and eight subcriteria such as aircraft price, operative cost, cruise speed, autonomy, seat comfort, cabin luggage compartment size, noise, and environmental pollution. Their aim is to propose a novel model for aircraft evaluation according to the airlines' needs [42]. Dožić et al. proposed a new methodology for the aircraft type selection problem with regard to different criteria that involve quantitative and qualitative aspects, three main criteria (aircraft characteristic, cost, and added value indicators), and ten subcriteria. They used opinions of experts from different airlines and universities for the analytic evaluation process. Fuzzy AHP was used due to the uncertainty of decision problems in their study [43]. Petkovics et al. studied different subjects from other academics. They selected the appropriate drone for the specific needs of farmers to collect the necessary data for precision agriculture using drones. They selected the best drone among the two drone types for data collection in agriculture [44].

In this context, this paper proposes a novel model for UAV selection, which aims to overcome the complexity of the UAVs' evaluation process. The integrated AHP-TOPSIS methods that are multicriteria decision-making methods are used for the selection process. These methods include a simple analytic process and basic calculations. The hybrid model proposed has a lower level of computational complexity, which facilitates its practical application. So, a systematic decision-making process was developed via the usability of the model and its applicability that helps decision makers in the UAV selection process.

The contribution of the paper could be perceived through two main issues: the first one is related to the selection criteria used as the model input, which is of crucial importance for decision-making and modeling, while the second one refers to the MCDM technique. Based on the analysis of the relevant literature, the criteria used in the decision-making process of aircraft type selection are identified. Also, the contribution of the paper is the proposed methodology for UAV selection among the aircraft selection problem based on the integrated MCDM methods for the first time. We see various studies of aircraft selection using MCDM methods done in our literature research. And we see a few studies such as planning of the UAV route and its mission planning. However, literature is limited to the UAV selection process using MCDM methods. Besides, numerous articles have recently been published about various UAV applications in military use and research, have been a major driver for advancing UAV technology, and have made a big contribution. However, academic studies on decision-making about UAVs are limited. This study will contribute to the literature in this respect.

\section{Multicriteria Decision-Making}

In this section, the AHP and TOPSIS methods are presented. This study utilizes two MCDM methods, AHP to determine the weights of criteria and TOPSIS to rank alternatives and select the best alternative UAV. A brief description and steps of each method are, respectively, provided as follows.

3.1. Analytic Hierarchy Process. Analytic hierarchy process (AHP) is a flexible and effective decision-making process, developed by Thomas L. Saaty. This method is useful, making the best decision for quantitative and qualitative aspects of a decision in establishing priorities. The AHP method has been applied in various fields: management, production, transportation, agriculture, industry, allocation, 
and distribution of resources in the complex decision problems solving strategic decisions. There are some causes of common usage of the AHP: (1) helps decision makers to find important degree in making simultaneous evaluation in the decision-making problem; (2) includes relatively basic mathematical calculation as compared to other analytic methods; (3) is flexible to be integrated in various decisionmaking methods such as ranking and programming models; and (4) has the ability to control mathematical calculations and judgment of decision makers [45]. A decision hierarchy structure of AHP includes three levels that are the goal, the criteria, subcriteria, and the alternatives. The hierarchy structure makes the problem more understandable and clearer for the decision makers at the decision process $[46,47]$. The selection process or calculating the weights in AHP has five major steps [48, 49]:

Step 1: determining decision problems, alternatives, and criteria. Establishing a matrix comparing the criteria and alternative pair wisely by using Saaty's scale. Saaty's scale: Extreme Importance-9; Very Strong Importance-7; Strong Importance-5; Moderate Importance-3; and Equal Importance-1.

Step 2: calculate the criteria weights with pairwise comparisons. So, find relative importance of weights of evaluation criteria in the hierarchy by using the scale, 1-9 points, of Saaty. And pairwise comparison matrices are created.

For example, $n \times n$ comparison matrix $a$ is created for $n$ criteria to the relative importance of the criterion $i$ and the criterion $j$. Among the $a$ matrix elements is the following connection:

$$
\begin{aligned}
& a_{i j}=1, \\
& a_{i j}=\frac{1}{a_{i j}} .
\end{aligned}
$$

Step 3: then, the normalized decision matrix is created Step 4: calculate the consistency index (CI) measured as follows:

Firstly, calculate the $\Lambda_{\max }$ value for total consistency;

$$
\mathrm{CI}=\frac{\% \Lambda_{\max }-n}{n-1}
$$

Step 5: calculate a consistency ratio (CR). If the CR is less than $0.10(\mathrm{CR}<0.1)$, then the ratio shows an acceptable level of consistency in the AHP. If CR is more than $0.10(\mathrm{CR}>0.1)$, the ratio is inconsistent as follows:

$$
\mathrm{CR}=\frac{\mathrm{CI}}{\mathrm{RI}}<0.10,
$$

with random index (RI) as given in Table 1.
TABLe 1: Random index (RI).

\begin{tabular}{lcccccccccc}
\hline $\begin{array}{l}\text { No. of } \\
\text { criteria }\end{array}$ & 1 & 2 & 3 & 4 & 5 & 6 & 7 & 8 & 9 & 10 \\
\hline RI & 0 & 0 & 0.58 & 0.90 & 1.12 & 1.24 & 1.32 & 1.41 & 1.45 & 1.49 \\
\hline
\end{tabular}

3.2. TOPSIS. The technique for order preference by similarity to ideal solution (TOPSIS) technique was established by Hwang and Yoon, an approach which presumes that each criterion tends toward a monotonically decreasing or increasing utility $[50,51]$. The necessitation of having the shortest distance to the positive ideal solution/the farthest distance from the negative ideal solution for the selection of alternatives is the fundamental concept of this technique [52]. It suggests the Euclidean distance strategy for this process that assesses the relative closeness of the selected alternatives to the ideal solution. Thus, a series of comparisons of these relative distances can be obtained with the preference order of the alternatives [53].

The first step includes the creation of an evaluation matrix which consists of $m$ alternatives and $n$ criteria. The intersection of each alternative with each criterion is given as $x_{i j}$, and therefore, the matrix can be described as $\left(x_{i j}\right)_{m \times n}$. The second step includes the normalization of the matrix:

$$
\begin{gathered}
R=\left(r_{i j}\right)_{m \times n}, \quad \text { where } r_{i j}=\left(\frac{x_{i j}}{\sqrt{\sum_{i=1}^{m} x_{i j}^{2}}}\right), \\
I=1,2, \ldots, m ; j=1,2, \ldots, n .
\end{gathered}
$$

The third step includes the calculation of the weighted normalized decision matrix:

$$
t_{i j}=r_{i j} * w_{j, 1}, \quad I=1,2, \ldots, m ; j=1,2, \ldots, n,
$$

where

$$
w_{j}=\frac{W_{j}}{\sum_{j=1}^{n} W_{j}}, \quad j=1,2, \ldots, n,
$$

so that $\sum_{j=1}^{n} W_{j}=1$, and $w_{j}$ is the original weight given to the indicator $v_{j}, j=1,2, \ldots, n$. On the other step, we calculate the worst alternative $(\mathrm{A}-)$ and the best alternative $(\mathrm{A}+)$.

In the decision process, equation (7) is used to determine the distance between each alternative and the positive ideal point. The distance between each alternative and the negative ideal point can be determined with equation (8) utilizing the same separation measure [54]:

$$
\begin{aligned}
& d_{i j}^{*}=\sqrt{\sum_{i=1}^{n}\left(V_{i j}-V_{i}^{*}\right)^{2}}, \\
& d_{i j}^{-}=\sqrt{\sum_{i=1}^{n}\left(V_{i j}-V_{i}^{-}\right)^{2},} \quad j=1,2, \ldots
\end{aligned}
$$


The relative closeness $\left(\mathrm{CC}_{j}^{*}\right)$ to the positive ideal solution can be calculated by the following equation

$$
\mathrm{CC}_{j}^{*}=\frac{d_{j}^{-}}{d_{j}^{-}+d_{j}^{+}}, \quad j=1,2, \ldots,
$$

where the $\mathrm{CC}_{j}^{*}$ index value lies between 0 and 1 . The larger the index value means the better the performance of the alternative. The TOPSIS technique usually deals with benefit and cost data. In this paper, the positive ideal solution (PIS) is the one with the lowest cost and most benefits of all alternatives, and the negative ideal solution (NIS) is the one with the highest cost and lowest benefits of all alternatives.

AHP and TOPSIS are used widely for decision process such as route selection [55], technology selection [56], project selection [57], location selection [58], and vehicle selection [59]. Besides, these methods have been used in studies like maintenance strategy selection [60], supplier selection [61], evaluation of low-emission energy technologies [62], optimization of maintenance strategies [63, 64], electric bus selection [65], strategic planning [66], and supplier selection [67].

\section{Selection of the Unmanned Aerial Vehicles}

The proposed decision model, composed of AHP and TOPSIS methods, consists of three stages. Firstly, identifying the criteria to be used in the model; second, finding the weight of criteria using AHP computations; and third, the final ranking of UAVs with TOPSIS.

To fulfill this selection process, the AHP-TOPSIS hybrid model has been selected in this research due to three causes. These three causes are simple mathematical and computational process, ranking the alternative locations based on their overall performance, and finally, the information requirements of the proposed framework are stratified into a hierarchy to simplify the information input and allow a selection problem to focus on a small area of the large problem. Besides, inconsistencies of the experts can be measured with $\mathrm{CR}$ values in these decision processes. A three-step methodology has been used in this study to the UAV selection process (see Figure 1).

4.1. Identification of the Criteria and Expert Team. UAVs have experienced major development and gained fastgrowing popularity worldwide during the last several decades. Nowadays, these vehicles are extensively used in various critical military and defence applications for reconnaissance, surveillance, and security reinforcement [68]. Evaluation of UAVs plays an important role in the design of an effective defence system. The producers of UAV are constantly innovating and improving their UAVs. These developing processes aim to answer to both needs of themselves and their potential customers. Besides, these processes are improved of technical features that deal with flight parameters such as flying range, speed, load capacity, and autonomous. In this scope, we evaluated six alternative UAVs for the defence area. We use seven performance criteria that are important criteria which belong to UAVs.

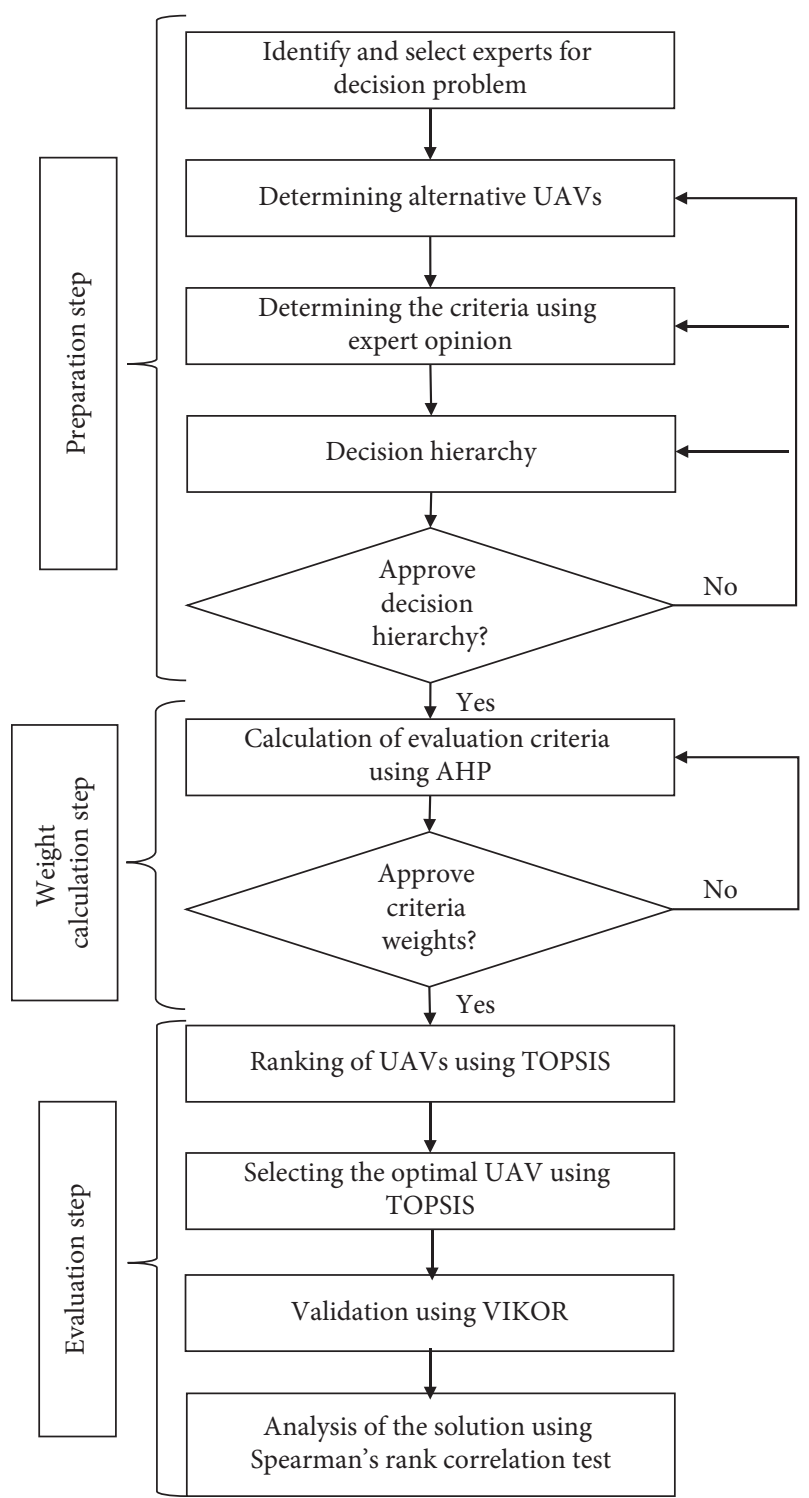

FIgURE 1: The schematic diagram for methodology.

These criteria are wingspan (C1), length (C2), payload capacity (C3), endurance (C4), cruise speed (C5), operational altitude (C6), and range (C7). These criteria are important for UAVs. For example, the criterion of the payload is one of the most important criteria for UAVs. With its capable payloads onboard, UAV can not only detect a target but also able to mark it with its laser designator and can attack. UAVs can take off, land, and fly fully autonomously for a mission without assistance from a pilot fully autonomously without assistance from a pilot. The payload capacity and variations are available for both civil and military applications. Criteria to be considered in evaluating UAVs are determined by the expert team. Furthermore, the judgments of experts are used in this methodology to evaluate the UAV selection process. The utilization of expert opinions is proposed in this methodology to define the problem statement, to identify the criteria for evaluating UAVs, and to the weight of the criteria in decision-making. The expert team determined six possible 
UAVs suitable for the needs for defence. The qualifications of experts are academic title, experience, and working area or institution, respectively: Expert 1, Prof Dr., 24, Optimization, Scheduling, and Decision-making/Expert 2, Assistant Prof, 12, Optimization and Energy/Expert 3, Assistant Prof, 10, Optimization/Expert 4, Assistant Prof, 12, Optimization/ Expert 5, Research Assistant, 4, Decision-making/Expert 6, Mechanical engineer, 22, Turkish land forces command/ Expert 7, Mechanical engineer, 23, Turkish land forces command. UAVs and their specifications are given in Table 2.

This study aims selection of the best UAV as in the goal shown in the hierarchy's top. Six alternatives and seven criteria are shown in the hierarchy structure in the same figure.

In AHP, the pairwise comparison matrix (Table 3) is formed to determine the criteria weights. Academic experts make evaluations using Saaty's 1-9 scale to determine the values of the criteria of pairwise comparison matrices. Table 4 shows the weight of criteria that are found as the result of comparisons with AHP. The criteria weights in the descending order are shown in Table 4 as can be seen that $\mathrm{C} 3$ and $\mathrm{C} 5$ were rated more important than the remaining criteria. Besides, $\mathrm{C} 4$ and $\mathrm{C} 7$ were rated relatively lower, and $\mathrm{C} 1, \mathrm{C} 2$, and $\mathrm{C} 6$ became the lowest-rated criteria. The consistency ratio is found by using formulas (1) and (2) and random index (RI). This value is an acceptable level. The decision hierarchy for selection of the best UAVs is shown in Figure 2.

It is to obtain a weighted decision table in the TOPSIS method using the criteria weights calculated by AHP. The resulting weighted decision matrix in TOPSIS process is shown in Table 5. Positive ideal and negative ideal solution values are shown in Table 6 . In this problem, $\mathrm{C} 1$ and $\mathrm{C} 2$ are cost criteria, whereas the other criteria, C3, C4, C5, C6, and $\mathrm{C} 7$, are benefit criteria.

Finally, the experts evaluated the six UAV alternatives for each evaluation criterion with AHP. The weight of the criteria has been calculated to ensure of the TOPSIS weighted valuation matrix for the UAVs. The AHP-TOPSIS methodology, the decision matrix described, is made in Table 2. In the following process, the decision matrix is normalized and is shown in Table 4, together with weighted values. Table 5 shows the calculated weighted normalized matrix. In the following step, the ideal and negative ideal solutions are determined using equations (3) and (4), shown in Table 6. Then, with equation (5), the distance from PIS and NIS is calculated, respectively, as their results are shown in Table 7. Eventually, the ranking has been calculated, and the score of each alternative is shown in Table 7.

Consequently, the distance of each vehicle from $\mathrm{A}+$ to A- can be currently calculated. The last step solves the similarities to an ideal vehicle. Based on CCi values in Table 7, the ranking of the UAVs in order is UAV-5, UAV-6, UAV-1, UAV-2, UAV-3, and UAV-4. AHP-TOPSIS model results indicate that UAV-4 is the best vehicle with the CCi value of 0.6173 .

Two different decision processes are applied as the TOPSIS method and the AHP-weighted TOPSIS method.
TABLE 2: UAVs and their specifications.

\begin{tabular}{lccccccc}
\hline \multirow{2}{*}{ Specif. } & \multirow{2}{*}{ Unit } & \multicolumn{6}{c}{ Alternative UAVs } \\
& & UAV-1 & UAV-2 & UAV-3 & UAV-4 & UAV-5 & UAV-6 \\
\hline C1 & $\mathrm{mm}$ & 3100 & 3400 & 5110 & 2200 & 6500 & 10500 \\
$\mathrm{C} 2$ & $\mathrm{~mm}$ & 1200 & 3110 & 4200 & 1000 & 4500 & 6500 \\
$\mathrm{C} 3$ & $\mathrm{~kg}$ & 6 & 50 & 5 & 1.5 & 50 & 70 \\
$\mathrm{C} 4$ & $\mathrm{hour}$ & 20 & 6 & 5 & 3 & 12 & 20 \\
$\mathrm{C} 5$ & $\mathrm{~km} / \mathrm{h}$ & 90 & 180 & 150 & 80 & 110 & 80 \\
$\mathrm{C} 6$ & $\mathrm{~km} / \mathrm{h}$ & 5000 & 4900 & 450 & 4500 & 5500 & 6800 \\
$\mathrm{C} 7$ & $\mathrm{~km} / \mathrm{h}$ & 1800 & 600 & 600 & 150 & 1300 & 150 \\
\hline
\end{tabular}

TABle 3: Pairwise comparison matrix.

\begin{tabular}{lccccccc}
\hline Crt. & C1 & C2 & C3 & C4 & C5 & C6 & C7 \\
\hline C1 & 1.000 & 3.000 & 0.333 & 0.333 & 0.333 & 0.200 & 0.333 \\
C2 & 0.333 & 1.000 & 0.333 & 0.333 & 0.333 & 0.200 & 0.200 \\
C3 & 3.000 & 3.000 & 1.000 & 1.000 & 3.000 & 3.000 & 0.333 \\
C4 & 3.000 & 3.000 & 1.000 & 1.000 & 3.000 & 1.000 & 0.333 \\
C5 & 3.000 & 3.000 & 0.333 & 0.333 & 1.000 & 1.000 & 0.333 \\
C6 & 5.000 & 5.000 & 0.333 & 1.000 & 1.000 & 1.000 & 0.333 \\
C7 & 3.000 & 5.000 & 3.000 & 3.000 & 3.000 & 3.000 & 1.000 \\
\hline
\end{tabular}

The CCi values obtained in this condition are presented in Table 7, with their comparisons with previous values. Based on unweighted CCi values, the ranking of the UAV systems in order is UAV-1, UAV-5, UAV-2, UAV-6, UAV-4, and UAV-3. The results changed according to the unweighted ranking. The rankings of the considered alternatives as derived by employing these two methods are exhibited in Figure 3.

4.2. Validation and Sensitivity Analysis of the Solution. TOPSIS and VIKOR (Vise Kriterijumska Optimizacija I Kompromisno Resenje) methods are distance-based similar methods. There is a difference between the decision process. While the VIKOR method uses linear normalization, TOPSIS uses vector normalization procedure. However, two methods have simple mathematical calculations and have been widely used for the complex decision process. In this section, we use the VIKOR method to validate TOPSIS results. Besides, Spearman's rank correlation test is used for control of the statistical similarities among the results of ranking methods. See, for a more detailed description of the VIKOR method and its decision-making process, [69-72].

The decision problem is solved separately with the VIKOR method, and AHP-weighted VIKOR solution results are given comparatively in Table 8 . The results of all methods are also shown in Figure 4 graphically.

The scores of criteria obtained by the AHP method are also used for two rankings. The rating scores of the TOPSIS applications are then compared with the ones obtained using the VIKOR method results by using Spearman's rank correlation test and proposed in Table 9. As the outcome of Spearman's rank correlation test, the results are provided in the same table. 
TABle 4: Criteria and their important score.

\begin{tabular}{lcccccccc}
\hline Crt. & C1 & C2 & C3 & C4 & C5 & C6 & C7 & Imp. score \\
\hline C1 & 0.0545 & 0.1304 & 0.0526 & 0.0476 & 0.0286 & 0.0213 & 0.1163 & 0.0645 \\
C2 & 0.0182 & 0.0435 & 0.0526 & 0.0476 & 0.0286 & 0.0213 & 0.0698 & 0.0402 \\
C3 & 0.1636 & 0.1304 & 0.1579 & 0.1429 & 0.2571 & 0.3191 & 0.1163 & 0.1839 \\
C4 & 0.1636 & 0.1304 & 0.1579 & 0.1429 & 0.2571 & 0.1064 & 0.1163 & 0.1535 \\
C5 & 0.1636 & 0.1304 & 0.0526 & 0.0476 & 0.0857 & 0.1064 & 0.1163 & 0.1004 \\
C6 & 0.2727 & 0.2174 & 0.0526 & 0.1429 & 0.0857 & 0.1064 & 0.1163 & 0.1420 \\
C7 & 0.0545 & 0.1304 & 0.0526 & 0.0476 & 0.0286 & 0.0213 & 0.1163 & 0.3155 \\
\multicolumn{2}{l}{ Consistency ratio (CR) } & & & & & & 0.08388 & $<0.10$ \\
\hline
\end{tabular}

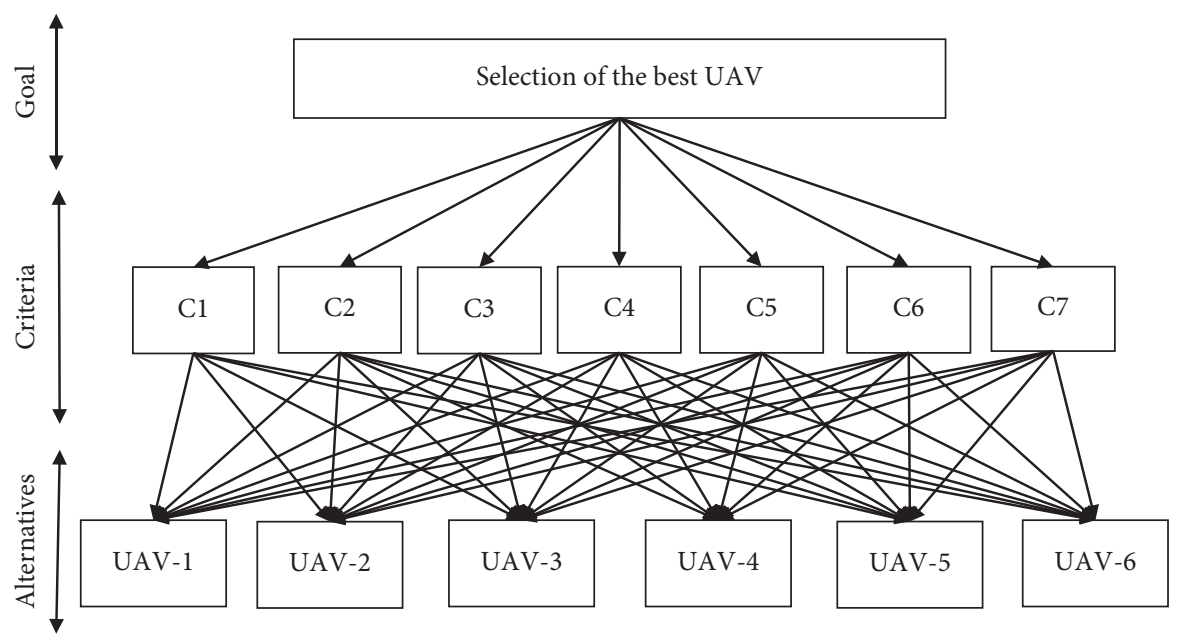

FIGURE 2: The decision hierarchy for the UAV selection process.

TABle 5: Weighted evaluation matrix for the UAVs.

\begin{tabular}{lccccccc}
\hline Alt. & C1 & C2 & C3 & C4 & C5 & C6 & C7 \\
\hline Weights & 0.0645 & 0.0402 & 0.1839 & 0.1535 & 0.1004 & 0.1420 & 0.3155 \\
UAV-1 & 0.014 & 0.005 & 0.011 & 0.096 & 0.030 & 0.059 & 0.238 \\
UAV-2 & 0.015 & 0.013 & 0.092 & 0.029 & 0.061 & 0.058 & 0.079 \\
UAV-3 & 0.023 & 0.018 & 0.009 & 0.024 & 0.051 & 0.005 & 0.079 \\
UAV-4 & 0.010 & 0.004 & 0.003 & 0.014 & 0.027 & 0.053 & 0.020 \\
UAV-5 & 0.029 & 0.019 & 0.092 & 0.058 & 0.037 & 0.065 & 0.172 \\
UAV-6 & 0.047 & 0.027 & 0.129 & 0.096 & 0.027 & 0.080 & 0.020 \\
\hline
\end{tabular}

Table 6: Determination of positive ideal and negative ideal solutions.

\begin{tabular}{lc}
\hline $\mathrm{A}+$ & $\mathrm{A}-$ \\
\hline 0.010 & 0.047 \\
0.004 & 0.027 \\
0.129 & 0.003 \\
0.096 & 0.014 \\
0.061 & 0.027 \\
0.080 & 0.005 \\
0.238 & 0.020 \\
\hline
\end{tabular}

In our study, the critical $Z$ value is 1.645 which is selected at the level of significance of $\alpha=0.05$. Each $Z$ value (TOPSIS, AHP-TOPSIS, VIKOR, and AHP-VIKOR) is higher than 1.645. It can be stated that the ranking provided by VIKOR applications is statistically similar to the other TOPSIS
TABLE 7: Final ranking for only TOPSIS and AHP-TOPSIS.

\begin{tabular}{lcccc}
\hline Alternatives & \multicolumn{2}{c}{$\begin{array}{c}\text { Only the TOPSIS } \\
\text { method }\end{array}$} & \multicolumn{2}{c}{$\begin{array}{c}\text { AHP-TOPSIS } \\
\text { method }\end{array}$} \\
& CCi & Ranking & CCi & Ranking \\
\hline UAV-1 & 0.6257 & 1 & 0.6623 & 2 \\
UAV-2 & 0.5578 & 3 & 0.4216 & 4 \\
UAV-3 & 0.3198 & 6 & 0.2374 & 5 \\
UAV-4 & 0.4283 & 5 & 0.1944 & 6 \\
UAV-5 & 0.5829 & 2 & 0.6747 & 1 \\
UAV-6 & 0.4755 & 4 & 0.4273 & 3 \\
\hline
\end{tabular}

applications. In conclusion, the most suitable UAV is selected by using AHP-TOPSIS. VIKOR and its applications support each result. However, the results show that there are small differences in ranking of methods.

\section{Conclusion}

The UAV selection is very important in decision-making process in terms of the success of the defense area. The objective of this paper is also to present an integrated MCDM approach for determination of the best UAV. Therefore, AHP and TOPSIS methods are used together.

The UAVs are an increasingly important element of many modern militaries and various civilian areas. So, there is a need for selection process for the UAVs among various technologies. Therefore, there are a lot of criteria affecting 


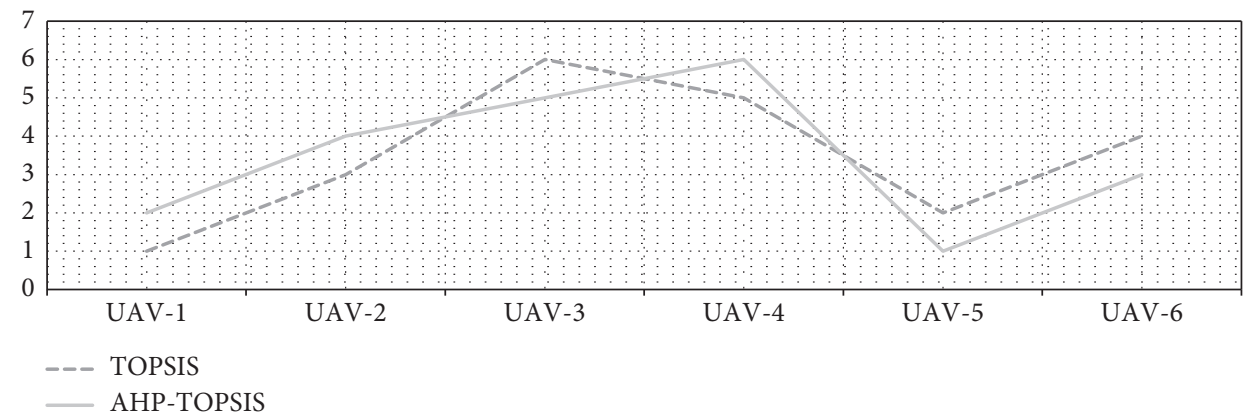

FIgURE 3: Comparison of TOPSIS and AHP-TOPSIS.

TABLE 8: Comparison of company ranking approaches.

\begin{tabular}{lccccccc}
\hline & \multicolumn{4}{c}{ Unweighted methods } & \multicolumn{3}{c}{ AHP weighted } \\
UAVs & \multicolumn{2}{c}{ TOPSIS (A) } & \multicolumn{2}{c}{ VIKOR (B) } & \multicolumn{2}{c}{ AHP-TOPSIS (C) } & \multicolumn{2}{c}{ AHP-VIKOR (D) } \\
& CCi & Rank & Pi & Rank & CCi & Rank & Pi \\
\hline UAV-1 & 0.6257 & 1 & 0.3905 & 3 & 0.6623 & 2 & 0.1733 \\
UAV-2 & 0.5578 & 3 & 0.2865 & 2 & 0.4216 & 4 & 0.4723 \\
UAV-3 & 0.3198 & 6 & 1.0000 & 6 & 0.2374 & 5 & 0.7565 \\
UAV-4 & 0.4283 & 5 & 0.9152 & 5 & 0.1944 & 6 & 1.0000 \\
UAV-5 & 0.5829 & 2 & 0.1705 & 1 & 0.6747 & 1 & 0.0699 \\
UAV-6 & 0.4755 & 4 & 0.8436 & 4 & 0.4273 & 3 & 0.7123 \\
\hline
\end{tabular}

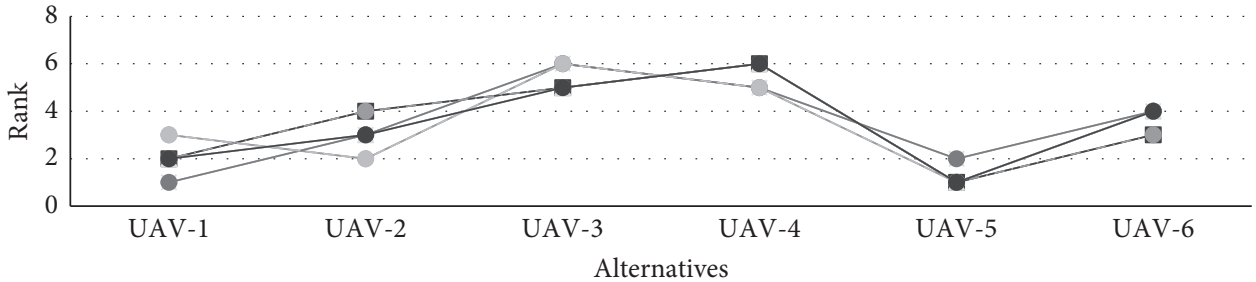

$\begin{aligned} & \text { A } \\ - & \text { B } \\ + & \text { C }\end{aligned}$

FIGURE 4: Comparison of ranking approaches.

TABLE 9: Spearman's rank correlation test.

\begin{tabular}{lccccc}
\hline \multirow{2}{*}{ Alternatives } & \multicolumn{5}{c}{ Ranking differences } \\
& A-B & A-C & A-D & B-C & B-D \\
\hline UAV-1 & -2 & -1 & -1 & 1 & 1 \\
UAV-2 & 1 & -1 & 0 & -2 & -1 \\
UAV-3 & 0 & 1 & 1 & 1 & 1 \\
UAV-4 & 0 & -1 & -1 & -1 & -1 \\
UAV-5 & 1 & 1 & 1 & 0 & 0 \\
UAV-6 & 0 & 1 & 0 & 1 & 0 \\
$\begin{array}{l}\text { Spearman's rank coefficient } \\
\text { (rs) }\end{array}$ & 0.829 & 0.829 & 0.886 & 0.771 & 0.886 \\
$\begin{array}{l}\text { Statistical significance value } \\
(Z)\end{array}$ & 1.853 & 1.853 & 1.981 & 1.725 & 1.981 \\
& & & & &
\end{tabular}

this decision process. All these criteria should be evaluated with various dimensions. Six alternatives under the seven criteria were evaluated, and the model solution was established with multicriteria decision-making in this study. Finally, the best UAVs among the alternatives were ranked.

5.1. Importance of This Study. Importance of this study is to help developing countries in the defence area for their decisions to select among the UAV alternatives. UAVs are project-based applications and are strategical vehicles for national security. So, this study will be a good guide which helps developing countries.

5.2. Recommendations for Future Studies. In future studies, the other MCDM methods such as analytic network process (ANP), ANP-TOPSIS, or fuzzy methods can be used, and the obtained results can be compared. The optimal solution of UAV selection can be done by mathematical models like goal programming or integer programming under resource constraints such as budget. It can be used as the zero-one goal programming model, by which the AHP/ANP priority 
weights can be combined with the objective function. Besides, one can focus on selection of specific criteria that are key performance drivers that can lead to informed selection of the UAV for successful decision-making. The criteria used in the proposed model can be improved with additional criteria.

The proposed model can be also used in the other important decision processes such as drone selection and attack helicopter selection. The model can also be used with minor modifications in other decision-making processes in the defence area. In addition, mathematical models such as goal programming can be combined with this model. Besides, the weapon and the weapon system selection for UAVs can be done with MCDM. The qualitative criteria together with the quantitative criteria such as human factor, flying, and handling qualities can be added to the proposed model.

At the same time, UAV selection process with MCDM can be used in traffic control and surveillance, infrastructure inspection, maintenance, security, precision agriculture, and also smart cities. Especially, the unmanned vehicle selection for traffic control and surveillance is a very important point for megacities.

\section{Data Availability}

The data used to support the findings of this study are available from the corresponding author upon request.

\section{Conflicts of Interest}

The authors declare that they have no conflicts of interest.

\section{Authors' Contributions}

Mustafa Hamurcu contributed to formal analysis, funding acquisition, investigation, methodology, project administration, and resources. Tamer Eren supervised and validated the study. Mustafa Hamurcu and Tamer Eren contributed to writing, reviewing, and editing of the paper.

\section{References}

[1] P. P. Y. Wu, "Multi-objective mission flight planning in civil unmanned aerial systems," Doctoral dissertation, Queensland University of Technology, Brisbane, Australia, 2009.

[2] M. Kahvec and N. Can, "Unmanned aerial vehicles: history, definition, legal status in Turkey and in the world," Selcuk University Journal of Engineering, Science and Technolog, vol. 5, no. 4, pp. 511-535, 2017.

[3] G. M. Saggiani and B. Teodorani, "Rotary wing UAV potential applications: an analytical study through a matrix method," Aircraft Engineering and Aerospace Technology, vol. 76, no. 1, pp. 6-14, 2004.

[4] N. Mohamed, J. Al-Jaroodi, I. Jawhar, A. Idries, and F. Mohammed, "Unmanned aerial vehicles applications in future smart cities," Technological Forecasting and Social Change, vol. 153, Article ID 119293, 2020.

[5] C.-H. Cheng, "Evaluating naval tactical missile systems by fuzzy AHP based on the grade value of membership function," European Journal of Operational Research, vol. 96, no. 2, pp. 343-350, 1997.
[6] C.-H. Cheng, K.-L. Yang, and C.-L. Hwang, "Evaluating attack helicopters by AHP based on linguistic variable weight," European Journal of Operational Research, vol. 116, no. 2, pp. 423-435, 1999.

[7] C.-H. Cheng and Y. Lin, "Evaluating the best main battle tank using fuzzy decision theory with linguistic criteria evaluation," European Journal of Operational Research, vol. 142, no. 1, pp. 174-186, 2002.

[8] Y. Gazibey, O. Kantemir, and A. Demirel, "Interaction among the criteria affecting main battle tank selection: an analysis with DEMATEL method," Defence Science Journal, vol. 65, no. 5, pp. 345-355, 2015.

[9] M. Dağdeviren, S. Yavuz, and N. Kılınç, "Weapon selection using the AHP and TOPSIS methods under fuzzy environment," Expert Systems with Applications, vol. 36, no. 4, pp. 8143-8151, 2009.

[10] J. Lee, S.-H. Kang, J. Rosenberger, and S. B. Kim, “A hybrid approach of goal programming for weapon systems selection," Computers \& Industrial Engineering, vol. 58, no. 3, pp. 521-527, 2010.

[11] H. Ashari and M. Parsaei, "Application of the multi-criteria decision method ELECTRE III for the weapon selection," Decision Science Letters, vol. 3, no. 4, pp. 511-522, 2014.

[12] J. M. Sánchez-Lozano, J. Serna, and A. Dolón-Payán, "Evaluating military training aircrafts through the combination of multi-criteria decision making processes with fuzzy logic. A case study in the Spanish Air Force Academy," Aerospace Science and Technology, vol. 42, pp. 58-65, 2015.

[13] J. M. Sánchez-Lozano, M. S. García-Cascales, and M. T. Lamata, "An analysis of decision criteria for the selection of military training aircrafts," in Soft Computing Based Optimization and Decision Models, pp. 177-190, Springer, Berlin, Germany, 2018.

[14] A. Göleç, F. Gürbüz, and E. Şenyiğit, "Determination of best military cargo aircraft with multi-criteria decision-making techniques," MANAS Journal of Social Studies, vol. 5, no. 5, pp. 87-101, 2016.

[15] B. Uçakcıoğlu and T. Eren, "Selection of investment projects in air defence industry by multi criteria decision making and goal programming," Journal of Aviation, vol. 1, no. 2, pp. 39-63, 2017.

[16] B. Sennaroglu and G. Varlik Celebi, "A military airport location selection by AHP integrated PROMETHEE and VIKOR methods," Transportation Research Part D: Transport and Environment, vol. 59, pp. 160-173, 2018.

[17] G. Guido, V. Gallelli, D. Rogano, and A. Vitale, "Evaluating the accuracy of vehicle tracking data obtained from unmanned aerial vehicles," International Journal of Transportation Science and Technology, vol. 5, no. 3, pp. 136-151, 2016.

[18] M. C. Tatum and J. Liu, "Unmanned aircraft system applications in construction," Procedia Engineering, vol. 196, pp. 167-175, 2017.

[19] A. Puri, K. P. Valavanis, and M. Kontitsis, "Statistical profile generation for traffic monitoring using real-time UAV based video data," in Proceedings of the 2007 Mediterranean Conference on Control \& Automation, IEEE, Athens, Greece, pp. 1-6, 2017.

[20] G. Salvo, L. Caruso, and A. Scordo, "Urban traffic analysis through an UAV," Procedia-Social and Behavioral Sciences, vol. 111, pp. 1083-1091, 2014.

[21] V. Braut, M. Culjak, V. Vukotic, S. Segvic, M. Sevrovic, and H. Gold, "Estimating OD matrices at intersections in airborne video-a pilot study," in Proceedings of the 35th International 
Convention MIPRO, IEEE, Opatija, Croatia, pp. 977-982, May 2012.

[22] J. Lee, Z. Zhong, K. Kim, B. Dimitrijevic, B. Du, and S. Gutesa, "Examining the applicability of small quadcopter drone for traffic surveillance and roadway incident monitoring," in Proceedings of the Transportation Research Board 94th Annual Meeting, Washington, DC, USA, January 2015.

[23] M. A. Khan, W. Ectors, T. Bellemans, D. Janssens, and G. Wets, "UAV-based traffic analysis: a universal guiding framework based on literature survey," in Proceedings of the 19th EURO Working Group on Transportation Meeting, EWGT 2016, Istanbul, Turkey, September 2016.

[24] E. N. Barmpounakis, E. I. Vlahogianni, and J. C. Golias, "Extracting kinematic characteristics from unmanned aerial vehicles," in Proceedings of the Transportation Research Board 95th Annual Meeting, Washington, DC, USA, January 2016.

[25] Y. Gül, "Applications of unmanned aerial vehicle (UAV) in open-pit mines," Geological Bulletin of Turkey, vol. 62, no. 1, pp. 99-112, 2019.

[26] M. Erdelj and E. Natalizio, "UAV-assisted disaster management: applications and open issues," in Proceedings of the 2016 International Conference on Computing, Networking and Communications (ICNC), IEEE, Kauai, HI, USA, pp. 1-5, February 2016.

[27] M. Hassanalian and A. Abdelkefi, "Classifications, applications, and design challenges of drones: a review," Progress in Aerospace Sciences, vol. 91, pp. 99-131, 2017.

[28] M. Akgül, H. Yurtseven, M. Demir, A. E. Akay, S. Gülci, and T. Öztürk, "Usage opportunities of generating digital elevation model with unmanned aerial vehicles on forestry," Journal of the Faculty of Forestry Istanbul University, vol. 66, no. 1, pp. 104-118, 2016.

[29] P. Wu, R. Clothier, D. Campbell, and R. Walker, "Fuzzy multi objective mission flight planning in unmanned aerial systems," in Proceedings of the 2007 IEEE Symposium on Computational Intelligence in Multicriteria Decision Making, IEEE, Honolulu, HI, USA, pp. 2-9, April 2007.

[30] P. P. Y. Wu, D. Campbell, and T. Merz, "On-board multiobjective mission planning for unmanned aerial vehicles," in Proceedings of the 2009 Aerospace Conference, IEEE, Big Sky, MT, USA, pp. 1-10, March 2009.

[31] N. Arıca, H. Cicibaş, and K. A. Demir, "Multi-criteria path planning model for unmanned aerial vehicles," Journal of Defence Sciences, vol. 11, no. 1, pp. 251-270, 2012.

[32] E. Caner, "Unmanned aerial vehicles," The Journal of National Security and Military Sciences, vol. 1, pp. 213-241, 2013.

[33] K. Kiracı and M. Bakır, "Using the multi criteria decision making methods in aircraft selection problems and an application," Journal of Transportation and Logistics, vol. 3, no. 1, pp. 13-24, 2018.

[34] C. Ercan and C. Gencer, "Literature review of dynamic unmanned aerial system routing problems and proposals for future studies of UASs," Pamukkale University Journal of Engineering Sciences, vol. 19, no. 2, pp. 104-111, 2013.

[35] K.-P. Lin and K.-C. Hung, "An efficient fuzzy weighted average algorithm for the military UAV selecting under group decision-making," Knowledge-Based Systems, vol. 24, no. 6, pp. 877-889, 2011.

[36] X. Sun, V. Gollnick, and E. Stumpf, "Robustness consideration in multi-criteria decision making to an aircraft selection problem," Journal of Multi-Criteria Decision Analysis, vol. 18, no. 1-2, pp. 55-64, 2011.

[37] Y. Ozdemir, H. Basligil, and M. Karaca, "Aircraft selection using analytic network process: a case for Turkish airlines," in
Proceedings of the World Congress on Engineering Vol. II, London, UK, July 2011.

[38] S. Dožić and M. Kalić, "Comparison of two MCDM methodologies in aircraft type selection problem," Transportation Research Procedia, vol. 10, pp. 910-919, 2015.

[39] T.-K. See, A. Gurnani, and K. Lewis, "Multi-attribute decision making using hypothetical equivalents and inequivalents," Journal of Mechanical Design, vol. 126, no. 6, pp. 950-958, 2004.

[40] C.-H. Yeh and Y.-H. Chang, "Modeling subjective evaluation for fuzzy group multicriteria decision making," European Journal of Operational Research, vol. 194, no. 2, pp. 464-473, 2009.

[41] L. F. A. M. Gomes, J. E. de Mattos Fernandes, and J. C. C. B. S. de Mello, "A fuzzy stochastic approach to the multicriteria selection of an aircraft for regional chartering," Journal of Advanced Transportation, vol. 48, no. 3, pp. 223237, 2014.

[42] G. Bruno, E. Esposito, and A. Genovese, "A model for aircraft evaluation to support strategic decisions," Expert Systems with Applications, vol. 42, no. 13, pp. 5580-5590, 2015.

[43] S. Dožić, T. Lutovac, and M. Kalić, "Fuzzy AHP approach to passenger aircraft type selection," Journal of Air Transport Management, vol. 68, pp. 165-175, 2018.

[44] I. Petkovics, J. Simon, A Petkovics, and Z. Čović, "Selection of unmanned aerial vehicle for precision agriculture with multicriteria decision making algorithm," in Proceedings of the 2017 IEEE 15th International Symposium on Intelligent Systems and Informatics (SISY), IEEE, Subotica, Serbia, September 2017.

[45] O. S. Vaidya and S. Kumar, "Analytic hierarchy process: an overview of applications," European Journal of Operational Research, vol. 169, no. 1, pp. 1-29, 2006.

[46] J. Ananda and G. Herath, "Evaluating public risk preferences in forest land-use choices using multi-attribute utility theory," Ecological Economics, vol. 55, no. 3, pp. 408-419, 2005.

[47] T. L. Saaty, The Analytic Hierarchy Process, RWS Publications, Pittsburgh, PA, USA, 1980.

[48] F. Dweiri, S. Kumar, S. A. Khan, and V. Jain, "Designing an integrated AHP based decision support system for supplier selection in automotive industry," Expert Systems with Applications, vol. 62, pp. 273-283, 2016.

[49] G.-N. Zhu, J. Hu, J. Qi, C.-C. Gu, and Y.-H. Peng, "An integrated AHP and VIKOR for design concept evaluation based on rough number," Advanced Engineering Informatics, vol. 29, no. 3, pp. 408-418, 2015.

[50] A. Jayant, P. Gupta, S. K. Garg, and M. Khan, “TOPSIS-AHP based approach for selection of reverse logistics service provider: a case study of mobile phone industry," Procedia Engineering, vol. 97, pp. 2147-2156, 2014.

[51] C. L. Hwang and K. Yoon, "Methods for multiple attribute decision making," in Multiple Attribute Decision Making, vol. 186, pp. 58-191, Springer, Berlin, Germany, 1981.

[52] C. Prakash and M. K. Barua, "Integration of AHP-TOPSIS method for prioritizing the solutions of reverse logistics adoption to overcome its barriers under fuzzy environment," Journal of Manufacturing Systems, vol. 37, pp. 599-615, 2015.

[53] J. Ding, "An integrated fuzzy TOPSIS method for ranking alternatives and its application," Journal of Marine Science and Technology, vol. 19, no. 4, pp. 341-352, 2011.

[54] E. Triantaphyllou, "Multi-criteria decision-making methods," in Multicriteria Decision Making Methods: A Comparative Study, pp. 5-21, Springer, Berlin, Germany, 2000. 
[55] M. Hamurcu and T. Eren, "An application of multicriteria decision-making for the evaluation of alternative monorail routes," Mathematics, vol. 7, no. 1, p. 16, 2019.

[56] M. Hamurcu and T. Eren, "Selection of monorail technology by using multicriteria decision making," Sigma Journal of Engineering and Natural Sciences, vol. 8, no. 2, pp. 303-314, 2017.

[57] A. Frini and S. Ben Amor, "A TOPSIS multi-criteria multiperiod approach for selecting projects in sustainable development context," in Proceedings of the 2015 International Conference on Industrial Engineering and Operations Management (IEOM), IEEE, Dubai, UAE, March 2015.

[58] Ş. Emeç and G. Akkaya, "Stochastic AHP and fuzzy VIKOR approach for warehouse location selection problem," Journal of Enterprise Information Management, vol. 31, no. 6, pp. 950-962, 2018.

[59] M. Erdoğan and İ. Kaya, "Evaluating alternative-fuel busses for public transportation in istanbul using interval type-2 fuzzy AHP and TOPSIS," Journal of Multiple-Valued Logic \& Soft Computing, vol. 26, no. 6, p. 2016, 2016.

[60] E. C. Özcan, S. Ünlüsoy, and T. Eren, "A combined goal programming-AHP approach supported with TOPSIS for maintenance strategy selection in hydroelectric power plants," Renewable and Sustainable Energy Reviews, vol. 78, pp. 1410-1423, 2017.

[61] V. Jain, A. K. Sangaiah, S. Sakhuja, N. Thoduka, and R. Aggarwal, "Supplier selection using fuzzy AHP and TOPSIS: a case study in the Indian automotive industry," Neural Computing and Applications, vol. 29, no. 7, pp. 555564, 2018.

[62] M. Ligus and P. Peternek, "Determination of most suitable low-emission energy technologies development in Poland using integrated fuzzy AHP-TOPSIS method," Energy Procedia, vol. 153, pp. 101-106, 2018.

[63] E. C. Özcan, T. Danışan, and T. Eren, "Hidroelektrik santralların en kritik elektriksel ekipman gruplarının bakım stratejilerin optimizasyonu için bir matematiksel model önerisi," Pamukkale Üniversitesi Mühendislik Bilimleri Dergisi, vol. 25, no. 4, pp. 498-506, 2019.

[64] E. Özcan, Ş. Gür, and T. Eren, "A hybrid model to optimize the maintenance policies in the hydroelectric power plants," Journal of Polytechnic, 2020, In press.

[65] M. Hamurcu and T. Eren, "Electric bus selection with multicriteria decision analysis for green transportation," Sustainability, vol. 12, no. 7, p. 2777, 2020.

[66] M. Hamurcu and T. Eren, "Strategic planning based on sustainability for urban transportation: an application to decision-making," Sustainability, vol. 12, no. 9, p. 3589, 2020.

[67] H. M. Alakaş, M. Bucak, and Ş. Kızıltaş, "AHP-TOPSIS ve AHP-VIKOR yöntemleri ile ambulans tedarik firması seçimi," Harran Üniversitesi Mühendislik Dergisi, vol. 4, no. 1, pp. 93-101, 2019.

[68] A. S. Saeed, A. B. Younes, C. Cai, and G. Cai, "A survey of hybrid unmanned aerial vehicles," Progress in Aerospace Sciences, vol. 98, pp. 91-105, 2018.

[69] S. Narayanamoorthy, S. Geetha, R. Rakkiyappan, and Y. H. Joo, "Interval-valued intuitionistic hesitant fuzzy entropy based VIKOR method for industrial robots selection," Expert Systems with Applications, vol. 121, pp. 28-37, 2019.

[70] B. Wang, J. Song, J. Ren, K. Li, H. Duan, and X. E. Wang, "Selecting sustainable energy conversion technologies for agricultural residues: a fuzzy AHP-VIKOR based prioritization from life cycle perspective," Resources, Conservation and Recycling, vol. 142, pp. 78-87, 2019.
[71] J. H. Kim and B. S. Ahn, "Extended VIKOR method using incomplete criteria weights," Expert Systems with Applications, vol. 126, pp. 124-132, 2019.

[72] A. Kumar, A. Aswin, and H. Gupta, "Evaluating green performance of the airports using hybrid BWM and VIKOR methodology," Tourism Management, vol. 76, Article ID 103941, 2020. 